\title{
Voltammetric Resolution of Dopamine in Complex Mixtures Using Graphene-Modified Electrode and Artificial Neural Networks ${ }^{\dagger}$
}

\author{
Marta Bonet-San-Emeterio *, Andreu Gonzàlez-Calabuig and Manel del Valle * \\ Department of Chemistry, Universitat Autònoma de Barcelona, Edifici Cn, 08193 Bellaterra, Barcelona, Spain; \\ andreu.gonzalez@uab.cat \\ * Correpondence: marta.bonet@uab.cat (M.B.-S.-E.); manel.delvalle@uab.es (M.d.V.) \\ + Presented at the 5th International Symposium on Sensor Science (I3S 2017), Barcelona, Spain, \\ 27-29 September 2017.
}

Published: 13 December 2017

Dopamine (DA) is an important catecholamine neurotransmitter that plays a relevant role in the human body's function. Disorders in DA concentrations are related to several neurological diseases such as Parkinson, Alzheimer and schizophrenia. Common physiologic interferences of this neurotransmitter via voltammetric determination are, among others, uric acid (UA), ascorbic acid (AA) and serotonin (5-HT).

The use of graphene derivatives in sensors field offer possibilities such as low-cost devices, easy monitoring, miniaturization and biocompatibility. Moreover, electrochemical detection techniques coupled with nanomaterials lead to the enhancement of sensor sensitivity and selectivity due to their chemical and electrochemical properties.

The goal of the study is to determine DA in biological systems using a laboratory made electrode, built employing a composite mixture formed by graphite and epoxy resin as transducer material. The surface of this transducer is coated via drop casting with electroreduced graphene oxide (ERGO) to obtain the finally used sensor with improved electrochemical response. Multicomponent determination is accomplished employing the complete voltammogram signal, after its processing using artificial neural networks (ANNs). The followed approach allowed the resolution of signal overlapping and the quantification of the individual species sought.

Conflicts of Interest: The authors declare no conflict of interest.

(C) 2017 by the authors. Licensee MDPI, Basel, Switzerland. This article is an open access article distributed under the terms and conditions of the Creative Commons Attribution (CC BY) license (http://creativecommons.org/licenses/by/4.0/). 